\title{
Coupled Analysis of Haze and Thermal Power
}

\author{
LIU Lu-ping ${ }^{1, ~ a, ~ Z O U ~ L o n g-s h e n g ~}{ }^{2, b^{*}}$ \\ ${ }^{1}$ Chongqing water resources and electric engineering college, Chongqing, 402160, China \\ ${ }^{2}$ Chongqing water resources and electric engineering college, Chongqing, 402160, China \\ a574898960@qq.com, bshl211@163.com
}

Keywords: thermal power; $\mathrm{SO}_{2}$; NOx; haze.

Abstract. Haze formation process and the reason were analyzed in the paper, and its harm to human health, particularly pollutants from thermal power industry was a key factor. In order to control the atmosphere environment worsen, and gradually improved the air quality, shorten time of the haze weather harm to residents. Government must formulate and implement stricter emissions standards, more sensible economic policies, encourage technological innovation and so on, to ensure to achieve the goal of eliminating haze.

\section{Introduction}

The haze swept through much of the land in our country once again, was suffering in Northeast Three Provinces etc on January 10, 2013. However, haze attacked North China Plain etc a second time on January 23. Scientific research had found that the haze hazard degree and breadth serious in our country year by year since 2010, Chongqing was not exceptional. Figure 1 was air quality of Chongqing from 2013 to 2014 in 338 cities around the country rankings changing trend. The figure showed that Chongqing's air was deteriorating. Statistical data manifested that haze days was 29.9 days in 2013, the highest record in 52 years $^{[1]}$.

The root cause of frequent haze, lied in the rough type of industry, enable a large increase of energy consumption, leading to thermal power installed capacity and power generation were rising rapidly. Total electricity in 2011 reached 4.713 trillion $\mathrm{kW} \cdot \mathrm{h}$, including thermal power generation $(81 \%)$, and coal was the most important and the main fuel of thermal power industry. In 2013 after the grid size and power were first in the world, the power capacity rose $9.25 \%$, to 1.247 billion $\mathrm{kW}$, and first in the world. The output growth by $7.52 \%$ to 5.4 trillion $\mathrm{kW} \cdot \mathrm{h}^{[2]}$. Therefore, from the regional energy structure, the power of the northeast region was given priority to with coal structure exist ${ }^{[3]}$ for the long term, the national energy with little difference in northeast China, the consumption of coal accounts for about eighty percent. In this paper, the formation of haze, and the degree to which the influence of thermal power industry, and pointed out that from the perspective of macro countermeasures reduced thermal power industry for air.

\section{The formation of haze and its harm}

Basic composition of haze included: particulate matter PM2.5, sulfur dioxide and nitrogen oxides, etc. They were thermal power industry, metal processing industry, and automobile exhaust, etc, the result of joint action. Research showed that thermal power industry was the major source of PM2.5, its emissions of sulphur dioxide and nitrogen oxides constantly growth, had become the key obstacles of PM2.5 management scheme.

\section{Generation of the haze}

PM2.5 is main component of the haze, also is the most serious harm, and it refers to the atmosphere diameter less than or equal to 2.5 micron particles. Although PM2.5 is only a few of earth's atmospheric composition, but it has important effect on visibility and air quality etc. The haze can produce, influenced by many factors, mainly include: contamination, air relative humidity and atmospheric conditions, topography, external transport, etc. To be clear, a high concentration of pollutants discharge is the internal cause, meteorological conditions conducive to the spread of the 
particulate matter is the external cause, only when these two conditions are, haze weather is produced, also explain high incidence of haze weather in autumn and winter.

\section{Dangers of the haze}

Dangers of the haze in several aspects: remarkable reduces atmospheric visibility, the transportation and brought great difficulty in the normal operation of the air; PM2.5 in human organs deposition, time is long, may cause the disease such as rhinitis, bronchitis, and even induce lung cancer. The haze also causes huge economic loss indirectly. In 2003 the environmental cost of economic losses caused by air pollution health as high as 1573-560 billion Yuan. Environmental protection environment on environmental economic accounting of the country's research results showed that environmental degradation cost and ecological destruction lost amounted to 1.39162 trillion Yuan, compared with last year increased by $9.2 \%$, accounted for about $3.8 \%$ of GDP in 2009.

\section{Role of thermal power to haze formation}

\section{Present situation and development of thermal power industry}

Since 1949, power industry had made considerable development, for example, power generation capacity was 001.73 million $\mathrm{kW}$, only 1949 in 2014 to 1.36019 billion $\mathrm{kW}$, the installed capacity increased 786.23 times in 65.In 2014 the national power generation was 5.5459 trillion $\mathrm{kW} \cdot \mathrm{h}$, the first in the world. But the per capita electricity consumption, electric power system automation, power transmission and distribution of economic indicators were behind the advanced level.

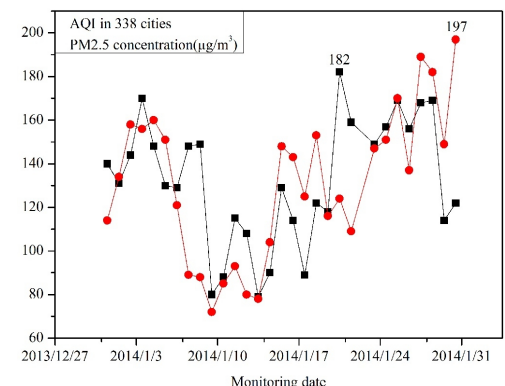

Fig. 1 Chongqing air quality ranking

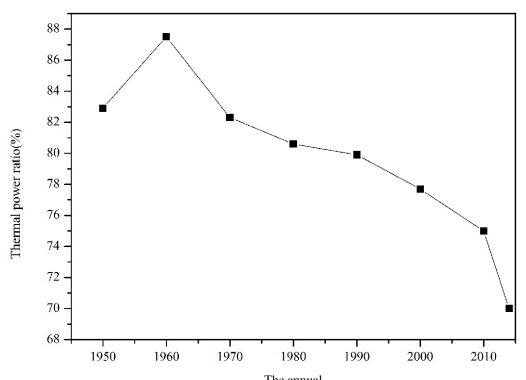

Fig.2 Proportion of thermal power generation

The same trend also reflected in power industry, it occupied a crucial place in the power supply, as was known to all, for the most part fire industry fuel was coal. Figure 2 was the proportion of coal-fired power electricity trends ${ }^{[4]}$, it showed that the proportion of thermal power in reducing gradually, down from $87.5 \%$ in the past to the current $70.0 \%$, down $17.5 \%$.

However, due to the rapid expansion of industrial, electricity installed capacity continued to increase, you could see the curve of figure 3, so the thermal power installed capacity were also constantly rising. Figure 4 was variation of new power generating capacity from 2012 to 2014, and figure 5 was thermal power installed capacity in total installed capacity of the percentage change in trend. Although thermal power installed capacity in increasing, but the proportion in the fall, it was worth a happy trend.

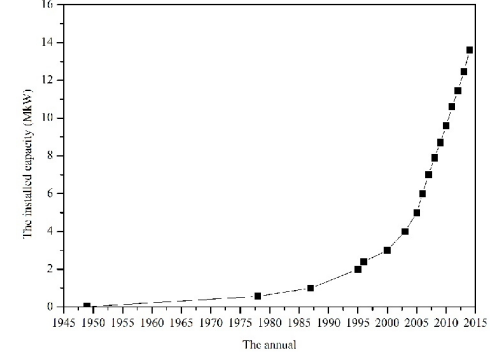

Fig.3 Total capacity variation

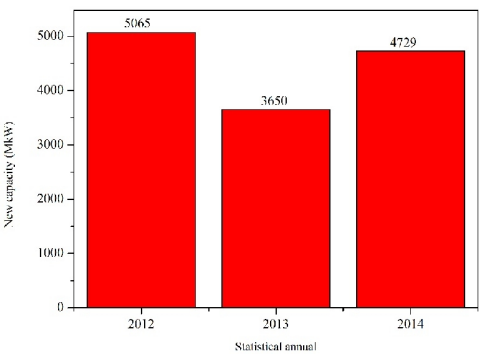

Fig.4 New capacity of thermal power

Coal burned to generate electricity at the same time, also brought a lot of sulfur dioxide, nitrogen oxides and smoke, and made it become one of the most important sources of PM2.5. At present, electricity structure, the proportion of electricity generation occupy absolute advantage was still the thermal power industry, about $78 \%$, coal thermal power industry accounts for around $50 \%$ of the total 
coal consumption. Coal-fired power plants, therefore, became "energy conservation and emissions reduction", the most important goals that figure 6 was various primary energy consumption ratio in 2011.

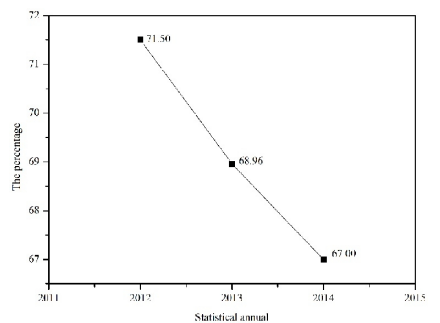

Fig.5 The proportion changing

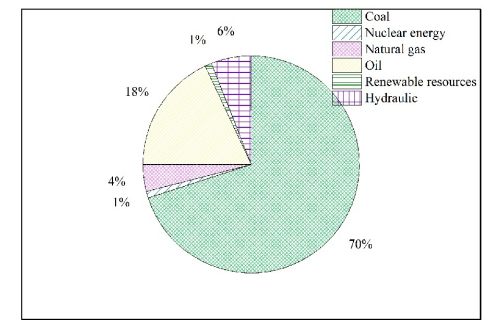

Fig. 6 All kinds of primary energy ratio

Main pollutants in exhaust emissions was $\mathrm{SO}_{2}$, its total emissions of 19.744 million tons, fell $3.40 \%$ year on year in 2014. NOx emissions was 20.78 million tons, fell $6.70 \%$ year on year in 2014. Table 1 was the main parameters in $2014^{[5]}$.

Table 1 The main pollutants in exhaust emissions

\begin{tabular}{|c|c|c|c|c|c|c|c|c|}
\hline \multicolumn{4}{|c|}{$\mathrm{SO}_{2}$ (Ten thousand tons) } & \multicolumn{5}{|c|}{ NOx(Ten thousand tons) } \\
\hline $\begin{array}{c}\text { Total } \\
\text { emission }\end{array}$ & $\begin{array}{l}\text { Industry } \\
\text { source }\end{array}$ & $\begin{array}{c}\text { Life } \\
\text { source }\end{array}$ & Central & $\begin{array}{c}\text { Total } \\
\text { emission }\end{array}$ & $\begin{array}{l}\text { Industry } \\
\text { source }\end{array}$ & $\begin{array}{l}\text { Life } \\
\text { source }\end{array}$ & $\begin{array}{l}\text { Motor } \\
\text { vehicle }\end{array}$ & $\mathrm{Ce}$ \\
\hline 1974.4 & 1740.3 & 233.9 & 0.2 & 2078.0 & 1404.8 & 45.1 & 627.8 & 0.3 \\
\hline
\end{tabular}

\section{Pollutants from thermal power}

Coal-fired power plants were mainly coal as fuel, coal burning after released a large amount of $\mathrm{SO}_{2}$, NOx, total suspended particles, but also produced high intensity noise. PM2.5 was complicated, including direct emissions of fine particle combustion process, and through atmospheric pollutants interacted to produce secondary particles. Haze was rooted for quenchless relies heavily on coal, 70\% energy came from cheap fossil fuels. From 2000 to today, coal consumption from 1.52 billion tons to 3.48 billion tons, an increase of $128 \% .2011$ annual growth rate of only $7.0 \%$, coal consumption accounted for more than $40 \%$ of the world's coal consumption ${ }^{[6]}$.

On the other hand, an unreasonable energy consumption, for example, coal accounted for $69 \%$, hydropower, nuclear power and other green energy accounted for only less than $8 \%$ in 2011. And the energy consumption situation of the United States was: oil, accounted for 36\%;Coal accounts for 20\%, green energy accounted for $17 \%$. While increased investment in green energy, and further expansion of the coal production and consumption, new installation of coal energy had only about $40 \mathrm{KMW}$ in 2013.By the end of 2015, China plans to increase coal production is 860 million tons, it is almost an annual output of 1.5 times of India. In 2013, according to every increase $1 \mathrm{KMW}$ new solar energy at the same time, also increased the new coal energy, $27 \mathrm{KMW}$ showed that degree of dependence on coal have been rising, and this directly from coal caused by climate change, and produced the consequences of haze weather.

\section{Measures of reducing pollution from thermal power industry}

\section{Discharge standards}

Environmental protection announced sulfur dioxide emissions of 22.18 million tons, NOx emissions of 24.04 million tons in $2012^{[7]}$.In order to purify air, must develop more stringent emission standards, on January 1, 2012, thermal power industry implemented the new coal-fired power plant air pollutants emission standards. In order to achieve the thermal power industry standard of pollutant emission, most of existing thermal power unit needed to improve the desulfurization, denitration and dust removal device. On February 19, 2013, the ministry in including 19 provinces (autonomous regions and municipalities) of 47 above ground level and cities, the focus of the control area, the thermal power, steel, petrochemical, cement, nonferrous metal, chemical industry and so on six big heavy pollution, new project coal-fired industrial boilers, thermal power, steel, petrochemical industry and coal-fired industrial boilers in existing projects, implementation of the special emission limits, 
enforced more stringent standards. In 2012, for example, the sulfur dioxide emissions was down more than 4.314 million tons in 2005, down 17\%.Power industry reduces 4.8 million tons, the contribution rate reached $111 \%$. Electric power industry in 2014 emissions continued to have fallen sharply, the sulfur dioxide, nitrogen oxides control efficiency is higher than other industries, the impact on air quality. Sulfur dioxide emissions by electric power industry had realized the sharp drop, regret was other industry also on the rise, led to increase the fog haze weather lasts.

\section{Economic leverage}

On August 27, 2013, countries increase a standard of renewable energy electricity price attached, by 0.8 cents $/ \mathrm{kW} \cdot \mathrm{h}$ to 1.5 cents $/ \mathrm{kW} \cdot \mathrm{h}$. To coal enterprise denitration electricity price compensation by 0.8 cents $/ \mathrm{kW} \cdot \mathrm{h}$ increase to 1.0 cents $/ \mathrm{kW} \cdot \mathrm{h}$. To adopt new technology of dust removal equipment renovation, carbon concentration less than $30 \mathrm{mg} / \mathrm{m}^{3}$ (key areas less than $20 \mathrm{mg} / \mathrm{m}^{3}$ ), and acceptance by the environmental protection department of coal-fired power generation enterprise support appropriate dust removal costs, electricity price compensation standard for $0.2 \mathrm{cents} / \mathrm{kW} \cdot \mathrm{h}^{[8]}$.

\section{Technological innovation}

The coal-fired power plants built before 2012 began to implement the new air pollutants emission standards, the standard and the European Union, Japan, Canada, Australia and other developed economies, compared to the current standards of harsher, figure 7 has clearly said. Its implementation would help to reduce the ash of the thermal power industry.

Coal consumption of thermal power industry was an important part of pollution control, if the coal consumption per $\mathrm{kW}$ declined year by year, for the improvement of air quality play an immeasurable role. Figure 8 was in recent years our country's coal consumption per kW variation, although was declining, but the size was not big enough, and there was a big gap with the international level, also had the very big space.
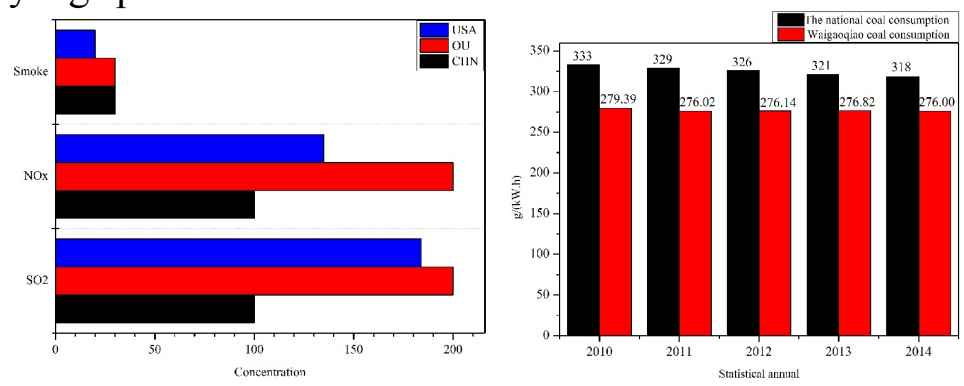

Fig. 7 Atmospheric pollutant emission Fig. 8 Unit coal consumption figure

By 2012, it had been put into operation unit power plant flue gas denitration total capacity more than 2.300 million $\mathrm{kW}$, accounted for $28 \%$ of the active thermal power unit capacity ${ }^{[9]}$.In the past, the pollution of using the method of comparison of a single pollutant, thermal power industry must improve in the design of pollution control technology, after formation of desulphurization and denitration, dust and other basic pattern of collaborative governance. Its characteristics are: 1) the flue gas coordination route of governance concept is advanced, realistic;2) using original equipment integration, small initial investment and operation cost;3) will not result in a new move of secondary pollution and energy consumption;4) has a good technical adaptability, can be applied to new or modified unit;5) has a good integrated performance between different modules, can be combined effectively according to the needs of different discharge ${ }^{[10]}$.

Domestic first to gas discharge standard unit "near zero emissions" coal-fired units. Its process was: low nitrogen burner + SCR + air preheater + efficient filter wet desulphurization wet electrostatic precipitators ${ }^{[11]}$. At present, the bag dusting could realize the dust concentration of the flue gas of the lowest, could provide the most stringent environmental standards with reliable technical support, the thermal power industry was the smoke efficient control and reliable security, but also reduced air pollutant emissions of mainstay ${ }^{[12]}$. K.wang, etc ${ }^{[13,14]}$ ePTFE membrane was analyzed and the traditional filter material in the material differences in structure and separation mechanism, through the experiment proved that ePTFE lower energy consumption than conventional filter material filter membrane filter $30441 \mathrm{~kW} \cdot \mathrm{h} / \mathrm{a}$. Activated coke flue gas purification scheme was mature, it greatly 
relaxed to the quality of the coal requirement, it was easy to make thermal power unit of $\mathrm{SO}_{2}, \mathrm{NOx}$, and dust discharged up to standard ${ }^{[15]}$. Desulfurization wastewater zero emissions technology, could make the coal-fired power plants really realizing wastewater zero emissions, put an end to the sewage discharge, more clean, environmental protection of construction of coal-fired power plants to provide the technical support, the wide prospect of engineering application ${ }^{[16]}$.

\section{Conclusion}

This paper analyzes the haze formation the process and the damage of the points out that the thermal power industry is the main source of PM2.5. After get to continue to improve, to make the air quality needs efforts from several aspects: 1)Need the support of national policy, especially the pollutants in the formulation and implementation of the standard. 2)Difference between a feed-in tariff gradient, according to the situation of pollutant emissions, power net order and feed-in tariff treatment respectively. 3)Support scientific and technological innovation, to provide technical support for the governance of pollutants.

\section{Reference}

[1] Fog 2013: coal for thermal power enterprise environmental cost will increase by 20\%[P]. 2014.

[2] Wang Zhi-xuan. The power industry present situation and outlook 2014 energy saving and emission reduction [P]. China Electric Power, 2014.

[3] Thermal power industry development in northeast China and fog prevention countermeasures[J]. Environmental Protection, 2013, 41(24): 23-25.

[4] Wang Li-ping. Our country present situation and development trend of thermal power unit[J]. Hunan electric power, 1997, (4): 52-56.

[5] China's environmental bulletin in 2014[B]. Environmental protection department of the People's Republic of China, 2015: 1-75.

[6] To disperse the haze: thermal power responsibility[P]. China energy news, 2013.

[7] Yan Su. "The most severe" industry a cap-and-trade policy, highlight the atmosphere pollution[P]. [8] Ma Yun-fei. A feed-in tariff cut, thermal power, 50 billion to pay for "smog"[P]. China Economic Herald, 2013.

[9] Zhang Hui. Under the haze of thermal power challenge[J].

[10] Li Jian-guo, Li Zhu-hai, Li Wei-dong, et ac. Coal-fired power plant flue gas treatment technology research together[J]. China's environmental protection industry, 2015, (5): 52-56.

[11] Jiang De-hou, Wang He-qin, Zhang Ying-shuai. Coal-fired power plant flue gas emissions "collaborative control" technology discussed in this paper[J]. China's environmental protection industry, 2015, (2): 21-26.

[12] Bag dust removal technology is the guarantee of coal-fired power plant flue gas discharging standard[J]. China's environmental protection industry, 2015, (2): 14-20.

[13] Wang Guo-hua, Chen Liu-ping, Zhang Feng, et ac. The application of membrane technology in coal-fired power plant flue gas dust removal [J]. Salt industry and chemical industry, 2015, 44(2): 50-53.

[14] Zheng Xiao-yi. Thermal power pollutants more collaborative technology governance effect in the early urban haze [P]. China International times, 2013.

[15] Dan Hui-jie, Yu Fu-sheng, Lei Ming, et c. Activated coke flue gas purification technology in the application prospect of large-scale coal-fired power plants[J]. Thermal power generation, 2015, 44(4): 1-6.

[16] Hu Shi, Ding Shao-feng, Fan Zhao-shi. Coal-fired power plant desulfurization wastewater zero discharge process research[J]. Clean coal technology, 2015, 21(2): 129-133. 
Funded project : Chongqing Water Resources and Electric Engineering College talent introduction project (KRC201406)

Author introduction: Zou Long-sheng (1973 -), male, associate professor, $\mathrm{PhD}$, research direction is energy saving and environmental protection. Email:shl211@163.com, tel: 15823165948 